\title{
O jogo produtivo da educabilidade/ governamentalidade na constituição de sujeitos universitários
}

\author{
Roberto Rafael Dias da Silva \\ Elí Terezinha Henn Fabris
}

Universidade do Vale do Rio dos Sinos, Programa de Pós-Graduação em Educação

O presente artigo é parte de um trabalho de investigação em que buscamos compreender os modos pelos quais os sujeitos universitários são constituídos na contemporaneidade, tomando como preferência analítica os enunciados que emergem das capas dos cadernos "Vestibular", suplemento publicado semanalmente pelo jornal Zero Hora (RS) e endereçado aos estudantes que aspiram ao ingresso na universidade. Do ponto de vista metodológico, em um primeiro momento, partimos de uma leitura dos enunciados que irrompiam das tramas enunciativas do material. A leitura dos enunciados levava em conta uma compreensão desses materiais como monumentos (Foucault, 2007a) que poderiam ser lidos em seu volume e em sua exterioridade. Em um segundo movimento investigativo, essa leitura das exterioridades buscou tornar visíveis os regimes de práticas que conduziam as condutas dos sujeitos, uma vez que tal inspiração teórica encaminhava a "um estudo das práticas organizadas através das quais somos governados e governamos a nós mesmos, o que chamaremos aqui de regimes de práticas ou regimes de governo" (Dean, 1999, p. 18).

Fomos desafiados a problematizar os modos como esses regimes de práticas potencializados pelo caderno "Vestibular" são movimentados por uma multiplicidade de estratégias e de táticas, colocando em circulação noções de conquista e de individualização. Ao propor-se a ensinar modos de ser, viver, estudar e trabalhar como um universitário, o caderno "Vestibular" institui práticas que regulam o campo de ação desses sujeitos e tende a colocá-los em posições estabelecidas, marcadas por um cenário em que talvez se experiencie a emergência de uma reconfiguração das sociedades disciplinares (Foucault, 2007b) ou, mais enfaticamente, condições de uma sociedade de controle (Deleuze, 2007). Partimos da perspectiva de que os tempos contemporâneos, em suas tramas de trabalho e de educação, são marcados pelas novas nuances do liberalismo em suas amplas potencialidades de governar. Assim, o liberalismo pode ser visto não articulado a uma filosofia política ou a uma tendência no campo da economia, mas de uma perspectiva foucaultiana, como "um refinamento da arte de governar, em que o governo, para ser mais econômico, torna-se mais delicado e sutil, de modo que 'para governar mais, é preciso governar menos"” (Veiga-Neto, 2000, p. 186). Com isso, de um ponto de vista mais amplo, pretendemos operar com a perspectiva de que a constituição de um sujeito universitário na contemporaneidade ocorre 
com base em múltiplas mediações das mídias - neste caso, o caderno "Vestibular" -, pois a mídia faz parte da rede discursiva que sustenta e coloca em circulação estratégias de governamentalidade, isto é, dispara ações que potencializam a ação do Estado.

Ao operar com o conceito de governamentalidade, não desejamos argumentar que ocorram ações verticais sobre as subjetividades dos sujeitos universitários. Antes disso, ao tomar os cadernos "Vestibular" como materialidade investigativa, desafiamo-nos a olhar para esses materiais e interrogar o presente, as condições que fazem com que seus enunciados se tornem problemáticos neste tempo. Logo, não tentamos buscar o que "Vestibular" postula aos seus leitores nem, consequentemente, marcar um lugar de crítica a uma nefasta indústria cultural. Apenas tomamos esse produto da mídia contemporânea como espaço enunciativo no qual se multiplicam enunciados acerca do constituir-se universitário nas tramas do contemporâneo.

Enfim, neste artigo defendemos o argumento de que, no jogo do liberalismo, no qual as relações entre trabalho e educação são entendidas em uma lógica empresarial, os sujeitos estudantes universitários constituem-se com base em um conjunto de estratégias articuladas a uma dinâmica concorrencial, no qual o estar na universidade passa a ser lido como uma conquista individual, pois, nessa ordem, os sujeitos tornam-se os responsáveis pelo seu sucesso ou pelo seu fracasso no mercado de trabalho. As práticas escolares, por estarem imersas nessas condições, são entendidas como espaços catalisadores dessas lógicas.

Organizamos este texto em três seções: na primeira, procuramos mostrar como as relações entre educabilidade e governamentalidade foram sendo tramadas ao longo do tempo e como são intensificadas pelas condições de uma centralidade da mídia; na segunda seção, trabalhamos com a possibilidade de que as redes de governamentalidade se sutilizam e se intensificam no jogo do neoliberalismo (norte-americano), dando condições para novas formas de regulação das subjetividades dos universitários; na terceira, apontamos como as noções de conquista são engendradas no jogo do neoliberalismo, desde as táticas de gestão dos tempos e das carreiras, fazendo emergir um "Universitário
S.A.”, um administrador de si na ordem da regulação do mercado.

\section{Entre a educabilidade e a governamentalidade: aproximações}

As aproximações entre as práticas educativas escolarizadas e os regimes das práticas de governamento são resultados de um longo processo histórico. Talvez pudéssemos dizer que, pelo menos desde o final século XVI, com a constituição do ideário filosófico da Modernidade, os espaços escolares são posicionados de forma estratégica para a consolidação de uma determinada configuração social. Ampliando o argumento, é possível dizer que a possibilidade de condução dos sujeitos a lugares específicos é uma prática significativa nos discursos pedagógicos clássicos; como exemplo, poderíamos remeter à maioridade kantiana ou à consciência crítica dos escritos freireanos.

Entretanto, em comum entre estas diferentes perspectivas pedagógicas, há algo que orienta a matriz pedagógica da Modernidade: a educabilidade. Pelo menos desde Comenius, os processos educativos partem desse pressuposto, ou seja, mobilizam-se desde a compreensão do ser humano como sendo dotado de razão e, como tal, capaz de compreender e transformar a natureza à sua volta. Na medida em que, desde a argumentação comeniana, os sujeitos são educáveis e todos devem aprender, são inúmeras as táticas modernas de condução desses sujeitos. A maioridade, a civilidade, a urbanidade, a emancipação são alguns dos lugares teleologicamente prometidos pelas práticas escolares de governamento. O que sistematizamos neste momento é que, em semelhante regime de articulação entre a educabilidade e a governamentalidade, as mídias contemporâneas ocupam privilegiado espaço nessa trama. Não somente operando disciplinarmente sobre os corpos dos sujeitos, a centralidade das mídias contemporâneas sutiliza as estratégias de atuação. Ampliando a argumentação comeniana, que afirmava que "a viabilidade do ideal pansófico reside na confiança na educabilidade do homem, dado que os escolarizáveis são a maioria" (Narodowski, 2001, p. 81), de forma mais específica, nesse jogo de relações, poderíamos afirmar que a educabilidade contem- 
porânea intensifica as práticas de governamentalidade. Esse é o movimento que desejamos tornar mais claro em nossa análise, pois há um deslocamento não só das práticas, mas dos dispositivos que atuam nessa contemporaneidade. Nossa hipótese é de que mídia e governamentalidade, em uma sociedade movida muito mais por dispositivos de seguridade que pelos disciplinares, mostram-se eficientes na visibilidade de uma outra maquinaria pedagógica, em que a escola é apenas mais uma agência para, com base na educabilidade, colocar em ação a governamentalidade. Ou ainda, diferentemente do que postulariam alguns entendimentos críticos acerca do Estado neoliberal, entendemos que “o abrandamento da presença do Estado não significa seu enfraquecimento; ao contrário, significa a sua presença em cada prática institucionalizada ou não. Em cada sujeito, está o Estado; não há como fugir à sua captura, cada vez mais sutil e eficiente" (Lopes, 2009, p. 166). Conseguiremos observar algumas dessas questões na descrição que faremos a seguir.

Considerando que a questão universitária tem estado na ordem do dia nas sociedades contemporâneas, os diferentes espaços de comunicação social têm dirigido algumas de suas publicações para os estudantes das instituições universitárias. Uma importante condição cultural de nossos tempos é a centralidade da “cultura da mídia" (Kellner, 2001), que se evidencia pela disseminação dos artefatos da mídia em todas as esferas sociais, marcando consideravelmente as subjetividades humanas produzidas na contemporaneidade. Nesse cenário, outra noção de comunicação passa também a constituir a pauta social de nosso tempo. A comunicação é entendida como "fenômeno extremo, vínculo e cimento social” (Silva, 2001, p. 180). Uma multiplicidade de produtos, demandas e perspectivas tem atravessado a constituição dos produtos midiáticos. Como tendência emergente desses cenários, visibiliza-se nas práticas jornalísticas a publicação de materiais impressos endereçados a grupos específicos dentro de determinada sociedade. Esses cadernos, encartes ou suplementos ${ }^{1}$ passam a compor a estrutura

${ }^{1}$ Uma possível diferença entre esses três conceitos estaria em sua periodicidade: os cadernos teriam publicação diária, os su- dos jornais - em especial, daqueles de maior circulação.

Os suplementos são estratégias relativamente recentes nas práticas jornalísticas, pulverizando-se ao longo dos anos 1990, visto que primeiramente se restringiam apenas a cadernos de cultura (Lustosa, 1996). Com os suplementos, aponta-se uma multiplicidade de temas e públicos diferentes dentro de um mesmo jornal. "Observamos que há uma multiplicação de jornais dentro do jornal, como se em sua proposta tradicional não coubessem mais as crescentes exigências dos leitores" (Lustosa, 1996, p. 171). Assim, os jornais objetivam atender o maior número possível de leitores de forma especializada, assumindo uma relação de interpelação com o seu público. Isso se dá não só pela qualificação dos meios técnicos de impressão e tratamento das notícias como também para atender a uma lógica do capitalismo contemporâneo, que tenta especializar seus produtos para melhor ampliar suas potencialidades de consumo (Bauman, 1998).

Dessa forma, a escolha de quais suplementos publicar não se define apenas por critérios jornalísticos. Ao dirigir-se a públicos cada vez mais específicos, os critérios tenderam a contemplar a abertura de novos mercados ou públicos potencialmente consumidores. "Cada suplemento foi surgindo à medida que se verificava a existência de um potencial econômico capaz de produzir uma receita publicitária suficiente para viabilizar o empreendimento" (Lustosa, 1996, p. 171). Com essa perspectiva, Rodrigues (2008), de outro registro teórico, aponta o caráter pragmático desses suplementos, pois assumem uma "destacada ênfase na produção de serviços".

Com uma dimensão especializada, os suplementos começaram a operar em outra dinâmica, não mais apenas de forma informativa, mas como "algo feito para se vender um espetáculo ou para se vender um produto cultural, menos do que para refletir sobre ele" (Rodrigues, 2008). Dentre essas tendências culturais das práticas jornalísticas de nosso tempo, uma produ-

plementos seriam semanais e os encartes teriam publicação aleatória. Alguns autores, como Lustosa (1996), tomam as noções de cadernos e de suplementos como equivalentes. 
tiva possibilidade de mercado tornou-se a publicação destinada aos campos educacionais em geral e, mais especificamente, para os estudantes que se preparam para o ingresso na educação superior. Materiais como o "Vestibular" (Zero Hora), o "Fovest" (Folha de S. Paulo), o "Gabarito" (Correio Brasiliense) e o "Vestibular" (Diário Catarinense), dentre outros, têm se multiplicado nas estratégias jornalísticas contemporâneas.

Esses materiais, ao se dirigir aos estudantes que se preparam para o ingresso na universidade, talvez operem como "guias de consumo" (Rodrigues, 2008), apresentando publicitariamente as maiores universidades, os cursos em ascensão ou mesmo aqueles que buscam manter-se ativos nos diferentes mercados regionais. Tais materiais são marcados não apenas pela apresentação dos processos seletivos e por anúncios de cursos preparatórios para os vestibulares, mas também pela indicação de modos de preparação ou mesmo da viabilidade dos mercados profissionais. Eles guiam, orientam, contribuem, criam pautas para os processos preparatórios de seus leitores. Com a ampliação dos mercados das universidades nas diferentes regiões do país, notando-se o acentuado aumento no número de matrículas nesse nível de ensino, os suplementos dirigidos aos estudantes universitários naturalizam suas ações nas tramas culturais de nosso tempo. Esses materiais, além de circular pelo cotidiano dos estudantes, também se fazem presentes nas práticas docentes, movimentando os currículos de escolas de ensino médio e cursos preparatórios. Cabe ainda enaltecer que eles serão tomados nas análises desde seus entendimentos, ou melhor, como um campo de inscrição das enunciações. Assim, também a gramática jornalística contribui para a potência e produção dos enunciados.

Avançando nessas movimentações analíticas, precisamos reiterar que os enunciados que emergem das capas do caderno "Vestibular", ao serem endereçados a determinados grupos, produzem sentidos específicos, o que os posiciona potencialmente no jogo educabilidade/governamentalidade. Isso se dá ao ensinar como estudar determinado conteúdo, como descansar na véspera da prova ou como preparar-se para o mercado de trabalho, dentre outros modos de condução das condutas. Junto a isso, podemos enfa- tizar como o ideário da educação comeniana passa a ser deslocado das possibilidades de aprendizagem para as possibilidades de empregabilidade. Parece-nos que, na contemporaneidade, nas tramas do capitalismo neoliberal, o que tem recebido maior peso nas práticas escolares, especialmente nos cursos universitários, são as competências, com ênfase para aquelas que mantêm os sujeitos ativos nas tramas do mercado profissional. Na próxima seção, buscaremos mostrar algumas das condições de possibilidade desse liberalismo.

\section{As tramas do liberalismo contemporâneo}

Milton Friedman, em seu clássico da teorização econômica contemporânea, Capitalismo e liberdade (1977), apresenta algumas das bases teóricas inspiradoras da ressignificação do liberalismo no final do século XX. O autor explica que as formas variáveis do capitalismo do final do século XIX e de boa parte do século XX teriam conduzido a uma perda dos sentidos clássicos do liberalismo, em especial no período posterior à Segunda Guerra, com a emergência dos modelos de Estados centrados na assistência, aqueles identificados como Estados de Bem-Estar Social. Segundo o economista, ganhador do Prêmio Nobel de Economia de 1976 e expoente da chamada Escola de Chicago, era preciso retomar os princípios do liberalismo clássico, uma vez que a liberdade política daquele período estava colocando em risco a liberdade econômica, prática central no interior dessa configuração.

Ao anunciar o objetivo principal do livro, Friedman expõe uma tematização que se tornará chave para os entendimentos dos cenários do capitalismo na contemporaneidade. O teórico da Escola de Chicago marca as duas teses que desenvolverá ao longo do livro: a empresa privada operando em um mercado livre e a relação entre governo e liberdade na condução das atividades econômicas. Para tanto, esse governo no "Estado da liberdade", tal como é nomeado por Friedman (1977), lança mão de duas estratégias: o papel regulador do governo (p. 33) e a responsabilização dos indivíduos (p. 21). Com essas estratégias, o neoliberalismo norteamericano movimenta-se, conforme o economista, na promoção da liberdade econômica: seja no nível 
das nações e das empresas (na ordem do capitalismo competitivo), seja no nível do indivíduo (como entidade principal da sociedade).

Ao mesmo tempo que observa a necessidade de práticas de governo reguladoras (insistimos, na sociedade e no indivíduo), Friedman vai tecendo inúmeras rejeições ao papel centralizado de um governo de Estado, entendendo que este fere a diversidade e a liberdade humanas. Recorre ao Estado de Bem-Estar Social, assim como às economias planificadas do socialismo, para mostrar o caráter de estagnação política e econômica que as práticas daquele promovem. Coloca-se, enfim, na defesa e na promoção da liberdade econômica. Tomar a liberdade econômica como objetivo último e deixar "os problemas éticos a cargo do próprio indivíduo" (Friedman, 1977, p. 21) fazem com que os modos de governar na contemporaneidade ganhem em sutileza e em refinamento. Michel Foucault, em suas aulas no curso O Nascimento da Biopolítica, mostrou os modos pelos quais o liberalismo era atravessado pela perspectiva de que "governa-se demais". Com isso, talvez possamos entender que a "reflexão liberal não parte da existência do Estado, encontrando no governo um meio de atingir essa finalidade que ele seria para si mesmo, mas da sociedade que vem a estar numa relação complexa de exterioridade e de interioridade em relação ao Estado" (Foucault, 1997, p. 91). Em outras palavras, com a premissa da liberdade econômica e com o consequente entendimento de que a liberdade política é pesada (afinal, governa-se sempre demais), a tarefa do governo é derivada para o conjunto da sociedade.

É preciso enfatizar que o novo liberalismo descrito em detalhes por Friedman intensifica essa gestão governamental e a amplia. O liberalismo clássico entendia a liberdade econômica na ordem da natureza, enquanto esse neoliberalismo, em especial esse que analisamos na versão norte-americana, entende que a liberdade econômica deve ser permanentemente produzida, estendida e ramificada. "Esse neoliberalismo busca estender a racionalidade do mercado, os esquemas de análise que ela propõe e os critérios de decisão que sugere a domínios não exclusivamente ou não prioritariamente econômicos" (Foucault, 1997, p. 96).
Com o entendimento de que a racionalidade governamental produzida nas tramas do neoliberalismo se multiplica para espaços não exclusiva ou prioritariamente econômicos é que, na pesquisa da qual este artigo deriva (Silva, 2008) a mídia é entendida como uma das estratégias que potencializam essas práticas governamentais. O liberalismo norte-americano também se propõe a pensar a educação, mesmo que em alguns momentos a atribua ao próprio indivíduo. Milton Friedman diferencia dois processos educacionais: um primeiro, tomado como educação geral, tornada possível a toda a população, e um segundo processo, identificado como preparação profissional e vocacional, destinado àqueles que ingressarão no mercado de trabalho. Essa preparação vocacional e profissional opera na égide de um novo conceito, o capital humano. "Sua função é aumentar a produtividade econômica do ser humano" (Friedman, 1977, p. 90). Nesse campo de relações, intensificam-se as de governamento da conduta, seja no nível do indivíduo, seja no nível da população. Essa teorização entende por capital humano (conceito atribuído ao economista Theodore Schultz nos anos 1950) o capital atribuído aos seres humanos em sua capacitação pessoal e profissional, funcionando como uma variável explicativa do desenvolvimento de uma sociedade. Pensamos que essas noções de capital humano operam no jogo de governamentalidade das subjetividades contemporâneas. Essas práticas de governamento serão discutidas na próxima seção.

\section{Estudantes universitários nas tramas do neoliberalismo}

Procurando historicizar rapidamente as noções de governo, poderíamos notar que sua compreensão ultrapassa o registro de um governo de Estado, pois essa prática é diluída pelos vários espaços sociais: o governo na casa, o governo na família, o governo na escola. Examinando esse conceito com base em uma perspectiva foucaultiana, vê-se que, na modernidade, ocorreu um deslocamento do espaço desse exercício de poder: não se seguia um modelo de soberania em que prioritariamente se administrava um território, mas emerge um modelo governamental no qual a 
população passa a ser o alvo (Foucault, 2007b). Esse deslocamento aparentemente simples evidencia uma nova forma de governar, apontada por Foucault desde a literatura antiMaquiavel no desenvolvimento de seu curso no Collège de France do ano de 1978.

Ao operarmos nesse registro, não estamos dizendo que não exista um governo de Estado; apenas afirmamos que ele faz mais que gerir um território. $\mathrm{Ou}$, de forma mais enfática, talvez estejamos assistindo a uma "governamentalização do Estado", uma multiplicação das atividades de governo do Estado conduzidas por uma racionalidade governamental. Essa racionalidade é explicitada quando o Estado "descobre a economia e faz da população o seu principal objeto" (Veiga-Neto, 2000 , p. 181). Diante disso, podemos notar que ocorreu uma progressiva estatização das ações de governo, fazendo outro uso do próprio poder. "Assim, é graças ao seu caráter microscópico e 'pervasivo' que o poder se torna quase invisível e, por isso, ainda mais efetivo" (Veiga-Neto \& Lopes, 2007, p. 952).

Com esse entendimento mais microscópico do poder, que tende a mostrar que as práticas de governo são mais sutis, pois "gerir a população significa geri-la em profundidade, minuciosamente, no detalhe" (Foucault, 2007b, p. 291), é que utilizamos o conceito de governamento para nos referir a essas práticas mais minuciosas (Veiga-Neto \& Lopes, 2007). Posicionando-nos em relação a esses entendimentos de governamento, chegamos até o conceito de governamentalidade, que nos serviu como ferramenta analítica ao longo da investigação. Estamos considerando por governamentalidade uma multiplicidade de práticas de governamento que tomam como alvo uma população e os saberes da economia como estratégias de ação (Foucault, 2007b). Assim, podemos considerar o liberalismo como um dos modos de pensar as estratégias de governamento. Insistimos que tomamos o liberalismo não como uma doutrina política ou econômica, mas como um conjunto de práticas que se dá em dois níveis: no do sujeito e no da população (Veiga-Neto, 2000). De forma mais simples, pode-se argumentar que essa racionalidade liberal é impulsionada por um racionalismo econômico extremo, "que vê o mercado não apenas como um mecanismo superior de alocação para a distribuição de recursos públicos escassos, mas também uma forma superior de economia política" (Peters, 2002, p. 212).

No contexto desse novo liberalismo é que se constitui o sujeito universitário visibilizado pelos enunciados de Vestibular/ZH. Um universitário produtivo economicamente, capaz de administrar sua vida pessoal e profissional em uma lógica empresarial, uma lógica de mercado. Esse sujeito toma a si mesmo como alvo de investimentos capazes de potencializá-lo para manter-se ativo no mercado de trabalho. O sujeito produzido e produtivo nessas paisagens neoliberais "é aquele que é capaz de participar competindo livremente e que é suficientemente competente para competir melhor fazendo suas próprias escolhas e aquisições" (Veiga-Neto, 2000, p. 199-200). Acerca das práticas educativas conectadas a essas noções, pode-se pensar a educação como espaço destinado à preparação desses recursos. Consideramos que é esse cenário que dá condições para que a ideia de conquista emerja dos materiais analisados - conquista produzida em um sentido concorrencial.

\section{A conquista é de sua responsabilidade!}

Tomamos como materialidade investigativa o caderno "Vestibular", suplemento semanal do jornal Zero Hora destinado a estudantes em processo preparatório para o ingresso na universidade. Zero Hora é um jornal diário com circulação regional, fundado em 4 de maio de 1964. Apresenta, em sua estrutura editorial, um conjunto de outros cadernos e suplementos endereçados a vários públicos, tais como: "Campo e Lavoura", "Esportes", "Empregos e Oportunidades", "Donna”, "TV Show", "Meu Filho", "Cultura" etc. É vinculado ao grupo Rede Brasil Sul de Comunicações (RBS), que tem o predomínio dos investimentos e recursos no campo das mídias (televisão, rádio, jornal etc.) em todo o estado do Rio Grande do Sul, abrangendo também o estado de Santa Catarina. O caderno analisado apresenta-se no mercado editorial gaúcho desde a metade da década de 1990, orientando e regulando os modos de preparação dos sujeitos universitários. 
Um dos enunciados emergentes das análises das 20 capas dos cadernos "Vestibular" que constituem a referida investigação é a forma como o ingresso na universidade é caracterizado como uma conquista. Conquista apontada não apenas como sedução, merecimento ou vitória em uma jornada, mas conquista em sentido concorrencial, objeto de uma ação disputada e vencida contra alguém. Mais especificamente, essa dinâmica concorrencial é constituída em sentido bélico, na possibilidade de ganhar a qualificação e o espaço no mercado de trabalho. Para tanto, algumas situações, dentre outras possíveis, podem ser visibilizadas nos discursos que emergem da exterioridade daquele material: estar na universidade é uma conquista somente possível para quem estuda de verdade; essa conquista constitui-se como produto de esforço e de treinamento constantes; essa conquista emerge ligada às oportunidades. De imediato, é possível notar os modos como a ideia de conquista é produzida fazendo com que os próprios estudantes sejam responsabilizados por ela.

O sociólogo Zygmunt Bauman (1998) tem argumentado que o processo de individualização das responsabilidades acerca do desempenho e do mérito tem uma história relativamente recente. No período do Estado de Bem-estar Social, em que os empregos eram duradouros e o futuro poderia ser planejado em virtude da estabilidade das relações de trabalho, "a indústria proporcionava trabalho, subsistência e segurança à maioria da população" (Bauman, 1998, p. 51). Ao Estado cabia a função de garantir os meios de manter a população empregável e, nos curtos períodos de desemprego, arcar com os custos sociais. Entretanto, as mudanças ocorridas nas últimas décadas fizeram com que essa configuração de Estado fosse tomada como "uma ameaça aos contribuintes", sob a alegação de que não era mais possível custeá-la. Diante disso, o Estado alterou sua posição e delegou suas responsabilidades, transferindo-as para os próprios sujeitos.

Consideramos que são essas paisagens de privatização das responsabilidades que dão condições de possibilidade para que esse enunciado da conquista individualizada possa circular. O estar na universidade é enunciado como uma conquista em um tempo-espaço marcado pela individualização das responsabilidades. A ideia de conquista não apenas responsabiliza os leitores de "Vestibular/ZH", como os interpela, capturando-os a entrar no jogo individual da busca pelo sucesso no mercado de trabalho. Dessa perspectiva, a conquista do ingresso em um curso superior pode conectar-se à noção de consumo, na medida em que não são quaisquer cursos que ganham visibilidade nas capas do suplemento analisado. "Ao contrário do processo produtivo, o consumo é uma atividade inteiramente individual. Ele também coloca os indivíduos em campos opostos, em que frequentemente se atacam" (Bauman, 1998, p. 54). A própria noção de formação universitária, ao ser tratada no jogo da conquista, faz da economia o saber constitutivo das relações sociais, pois o que importa consideravelmente é uma relação de custo-benefício: fazer um curso superior toma a condição de ser um "investimento em si mesmo".

Quanto a essa estratégia da conquista, escolhemos descrever duas táticas que atuam na multiplicação desse processo: a gestão dos tempos e a gestão das carreiras dos sujeitos universitários. A mobilização articulada dessas duas táticas posiciona tais sujeitos em um jogo permanente de busca pela conquista. Conquista essa que, conforme argumentamos antes, extrapola os limites do próprio artefato e do próprio processo formativo dos sujeitos. Nesse jogo produtivo entre a educabilidade e a governamentalidade coloca-se em ação um conjunto de estratégias e de táticas. Desde os estudos foucaultianos do final da década de 1970 é possível entender por estratégias os saberes ou as racionalidades que mobilizam a constituição contemporânea de um determinado sujeito; no caso, o universitário. Logo, os grandes regimes de verdade do neoliberalismo, como a empregabilidade ou a conquista individual, operam como meios empregados para atingir determinados fins (Foucault, 1995). Por táticas, entendemos as ações/ práticas micropolíticas que conduzem as condutas dos sujeitos, encaminhando para formas específicas de governamento das subjetividades. 
A primeira tática que descreveremos refere-se à gestão do tempo, a qual parte da perspectiva de que é preciso aprender a conciliar o tempo de lazer e o tempo de estudo, conseguindo priorizar o segundo. O sujeito é convocado a administrar racionalmente seu tempo, medindo as possibilidades e perseguindo prioridades. Considerando que, na cultura do novo capitalismo (Sennett, 2006), não há longo prazo, o estudante é responsabilizado pela obtenção de resultados rápidos em um tempo marcado pela flexibilidade. Flexibilidade no sentido de saber adaptar-se a circunstâncias variáveis. Na nova configuração capitalista, a organização do tempo faz-se importante, visto que os trabalhadores operam no circuito do "flexitempo" (Sennett, 2001, p. 66), em que "o circuito de trabalho é um mosaico de pessoas trabalhando em horários diferentes, mais individualizados". Um tempo flexível e produtivo é aquele que convida os sujeitos universitários a ingressar no jogo neoliberal.

Um dos modos pelos quais a tática de gestão do tempo é mobilizada refere-se ao entendimento de que é preciso saber escolher prioridades. A capa a seguir começa a constituir um primeiro campo de recorrências.

Figura 1 - Jornal Vestibular Pecados

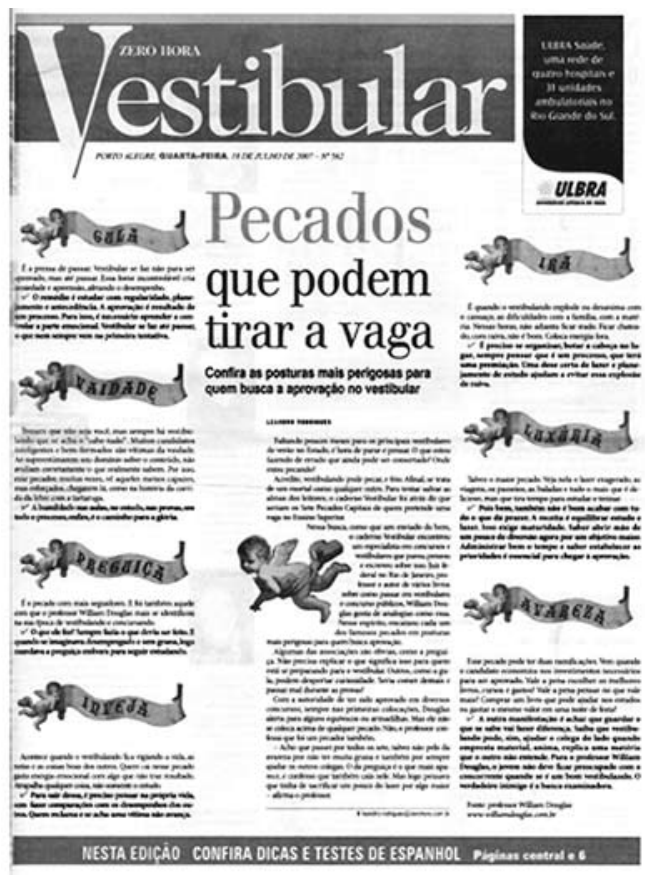

Escolher as prioridades encaminha para uma perspectiva individualizada que se movimenta no campo das liberdades. O sujeito universitário escolhe o que é melhor para si; nesse jogo de escolhas, na medida em que deseja obter sucesso em sua vida profissional, opta por ter cuidados com o tempo de lazer, entendido como um tempo sem aproveitamento. "Um pecado." Ao optar por tempo de diversão, passeios ou festas, o sujeito é interpelado a sentir-se culpado, pois, apesar de a lógica desse tempo operar na égide da flexibilidade, há um sistema de regulação em movimento. As tramas de poder dessa regulação começam a tornar-se mais nítidas no fragmento a seguir, que mostra um conjunto de possibilidades de planejamento para o uso do tempo.

\begin{tabular}{|l|}
\hline $\begin{array}{c}\text { Março, abril e maio } \\
\text { Planejamento e organização } \\
\text { Planeje a sua estratégia de estudos. Isso envol- } \\
\text { ve a escolha do colégio, do cursinho, a definição do } \\
\text { local de estudo em casa e as horas de lazer. Calcule } \\
\text { o tempo dedicado às aulas, ao estudo em casa, pre- } \\
\text { vendo deslocamentos, atividade física e descanso. } \\
\text { Elabore um horário e siga à risca todos os dias. } \\
\text { Em pouco tempo, você estará adaptado ao novo } \\
\text { ritmo e tudo ficará mais fácil. Eleja uma atividade } \\
\text { física em que você possa manter a regularidade, } \\
\text { economizando tempo. O lazer deve ser mantido, } \\
\text { mas faça seus pais e seus amigos entenderem que } \\
\text { você tem um objetivo. }\end{array}$ \\
\hline
\end{tabular}

Fonte: Vestibular/ZH, edição 559, 27 de junho de 2007*

Esse fragmento prescreve uma receita de aproveitamento do tempo para os meses de março, abril e maio. Visto que o estudante realizará suas provas do concurso vestibular somente em dezembro, pode-se notar como essa gestão do tempo planeja praticamente todo o ano desse sujeito. Essa gestão do tempo pressupõe uma rotina de atividades, pois busca regularidades. Tais regularidades evidenciam-se em expressões como "seguir à risca", "economizando tempo" ou

* Os grifos nos fragmentos dos materiais investigativos foram realizados pelos autores da investigação. 
"calcule o tempo". A ocupação do tempo do sujeito implica uma otimização, na medida em que amigos e familiares são convocados a entender que o estudante tem um objetivo. Para gerir bem o tempo, é preciso deixar as metas claras.

A mobilização dessa tática opera não apenas ensinando como preparar-se para uma prova ou como otimizar seu tempo. Mostra que não basta apenas estudar; é preciso administrar-se para ter uma série de condutas em diferentes espaços e com diferentes grupos culturais. Além de receitas de conduta, rotinas de práticas a serem seguidas ao preparar-se para uma prova ou mesmo prescrições de como alcançar um caminho de sucesso, esse conjunto de preceitos produz muito mais do que um disciplinamento - produz regimes de governamento, porque dispõe de tal modo da vida desses estudantes que eles são conduzidos não a um bem comum, "mas a um objetivo adequado a cada uma das coisas a governar. O que implica, em primeiro lugar, uma pluralidade de fins específicos" (Sennett, 2006), ou seja, no caso aqui analisado, como constituir-se como estudante universitário, como preparar-se para uma prova, como relacionar-se com a família, como ocupar o tempo de lazer etc. Significa não só ser aprovado no vestibular e entrar em uma faculdade, mas aprender a submeter-se às dinâmicas de cada curso para tornar-se um estudante que, ao atuar de uma determinada forma, se tornará um profissional que atuará sob determinadas condições.

A segunda tática que escolhemos analisar é a gestão das carreiras, visto que a questão do trabalho nas configurações da sociedade capitalista tem produzido numerosos deslocamentos acerca dos entendimentos modernos sobre essa noção. Há muito as pesquisas sociológicas mostram os elevados índices de desemprego, as sobrecargas de atribuições para um indivíduo permanecer no seu emprego ou pelo menos manter-se empregável e até os novos modos de gestão empresarial do trabalho e do capital. Em sintonia com esse tempo de mudanças, o caderno "Vestibular" potencializa algumas táticas que tendem a gerenciar a formação dos sujeitos universitários, orientando-os a permanecer ativos nesta "sociedade das capacitações"
(Sennett, 2006). No limite, as táticas mobilizadas por esse material operam no sentido de mostrar modos possíveis de aproximar trabalho e lazer, regulando, dessa maneira, a formação para uma autoformação flexível e permanente.

O grande desafio posto aos sujeitos que buscam espaço no mercado de trabalho é a forte tendência de manter-se desempregado, ou "o fantasma da inutilidade" (Sennett, 2006). O sociólogo Richard Sennett explica que, na cultura do novo capitalismo, há preocupação em separar a mão de obra útil daquela que deverá ficar temporariamente nos imensos contingentes de reserva. Outra preocupação está no caráter individualizante dos processos de seleção, que, em "seleções de talentos", tendem a criar critérios excessivamente subjetivos e passam a fazer comparações pessoais.

Esses critérios apontados por Sennett como excessivamente subjetivos tendem a fazer significativas aproximações entre trabalho e lazer. Quanto mais prazerosa for a atividade para o sujeito, maiores condições ele terá de planejar sua carreira. Cabe lembrar que esse planejamento das carreiras opera em campo de flexibilidades; dessa forma, não se trabalha com o longo prazo. A capa a seguir apresenta alguns desses aspectos.

Figura 2 - Jornal Vestibular Games

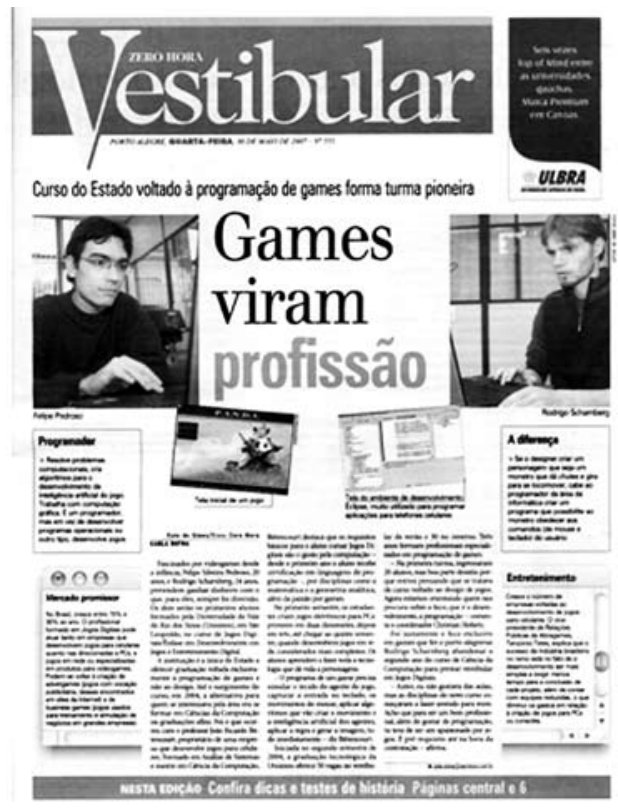


A manchete da capa apresenta uma composição interessante, "Games viram profissão". Os jogos eletrônicos, produto de desejo de adolescentes e jovens, podem tornar-se não apenas uma fonte de renda, mas também uma carreira profissional. A reportagem trata de um curso superior em jogos digitais. Ao longo do texto, dois estudantes relatam suas experiências em outros cursos, assim como o quanto têm prazer em estar estudando nessa área. $\mathrm{O}$ fragmento a seguir traz duas perspectivas da capa que fazem do prazer uma prerrogativa da gestão das carreiras na contemporaneidade.

- Na primeira turma, ingressaram 20 alunos, mas boa parte desistiu porque entrou pensando que se tratava de curso voltado ao design de jogos. Agora estamos orientando quem nos procura sobre ofoco, que é o desenvolvimento, a programação - comenta o coordenador Christian Hofsetz.

Foi justamente ofoco exclusivo em games que fez o porto-alegrense Rodrigo Scharnberg abandonar o segundo ano do curso de Ciência da Computação para prestar vestibular em Jogos Digitais.

- Antes eu não gostava das aulas, mas as disciplinas do novo curso começaram a fazer sentido para mim. Acho que para ser um bom profissional, além de gostar de programação, tu tens que ser um apaixonado por jogos. É pré-requisito até na hora da contratação - afirma.

Fonte: Vestibular/ZH, edição 555, 30 de maio de 2007

A tática de gestão das carreiras trama-se em um cenário de precarização do trabalho. Incentiva buscar novos desafios, assim como buscar prazer nas atividades profissionais, sem perder de vista que as noções de emprego estável e carreira planejada estão em rápido processo de deslocamento. A política da gestão das carreiras diz que há trabalho para todos, basta qualificar-se permanentemente. Hardt e Negri (2002, p. 359) explicam que, nos tempos de Império, "quanto mais desregulado for o regime de exploração, mais trabalho haverá. Esta é a base sobre a qual as novas segmentações de trabalho são criadas". A política imperial do trabalho implica gerenciamento microadministrativo dos sujeitos e de suas possibilidades de trabalho (carreiras).

\section{A conquista como um programa formativo}

Pretendemos mostrar como o conjunto produtivo das capas de "Vestibular" vai produzindo um programa formativo que privilegia a conquista permanente, tanto pela gestão das carreiras quanto pela gestão dos tempos. Não trazemos a pretensão de mostrar como isso acontece nas escolas propriamente ditas, uma vez que partimos do pressuposto de que esses artefatos produzem sentidos. Especificamente, queremos mostrar como esses sentidos ressoam nas culturas contemporâneas, interpelando sujeitos e constituindo suas subjetividades com base em determinadas táticas e estratégias. Tal programa pode ser lido, enfim, na multiplicidade de sentidos que irrompe das tramas enunciativas do material analisado, o caderno "Vestibular".

Conforme vimos mostrando neste texto, as relações entre a governamentalidade e a educabilidade não são recentes; entretanto, intensificaram-se no jogo do neoliberalismo norte-americano. As tramas de governamento destes tempos conduzem a processos de responsabilização e individualização dos próprios sujeitos. A pesquisa que realizamos acerca da constituição de sujeitos universitários na contemporaneidade indica que a conquista é tomada como um enunciado produtivo. Logo, nosso desafio para finalizar esta argumentação está em mostrar rápidas aproximações dessa noção de conquista com as práticas escolares, uma vez que entendemos a escola como sendo deste mundo e, como tal, imersa em múltiplas redes. Entendemos que as produtivas relações entre trabalho e educação passam a ser lidas sob um registro empresarial em que conceitos como flexibilidade, empreendedorismo ou realização pessoal dão corpo a essas novas discursividades.

Para provisoriamente finalizar estas problematizações, procuramos mostrar alguns dos modos pelos quais as mídias contemporâneas potencializam um conjunto de táticas e estratégias que sustentam a 
governamentalidade neoliberal, especificamente no jogo educabilidade/governamentalidade. A conquista emerge não só como um enunciado das tramas deste tempo como também opera na forma de um regime de práticas, dinamizando a condução das condutas dos sujeitos universitários. Os sentidos emergentes dos cadernos "Vestibular", colocados em análise, entendidos como fabricações culturais, e como tais regidas pelas movimentações do "novo capitalismo" (Sennett, 2006), tornam-se intensamente produtivos. A centralidade da conquista nas práticas escolares contemporâneas conduz à individualização e à responsabilização dos sujeitos, mediados pela produção de uma pauta de consumo que posiciona o acesso ao saber universitário no campo individual - acesso obtido mediante uma competição acirrada, na qual as responsabilidades são privatizadas. Podemos afirmar, enfim, que o jogo produtivo da educabilidade/governamentalidade coloca em ação, nas capas de "Vestibular", outros modos de pensar os processos formativos, os quais poderíamos nomear provisoriamente currículos da conquista, marcando uma produtiva relação com o mercado.

\section{Referências bibliográficas}

BAUMAN, Zygmunt. O mal-estar da pós-modernidade. Rio de Janeiro: Jorge Zahar, 1998.

DEAN, Mitchell. Governmentality: power and rule in modern society. London: Sage, 1999.

DELEUZE, Gilles. Política. In: DELEUZE, Gilles. Conversações. São Paulo: Editora 34, 2007. p. 209-226.

FOUCAULT, Michel. A arqueologia do saber. 7. ed. Tradução Luís Felipe Baeta Neves. Rio de Janeiro: Forense Universitária, 2007a.

A governamentalidade. In: Machado, Roberto (Org.).

Microfisica do Poder. São Paulo: Graal, 2007b. p. 277-293.

O nascimento da biopolítica. In: FOUCAULT, M.

Resumo dos cursos do Collège de France (1970-1982). Rio de Janeiro: Jorge Zahar, 1997. p. 87-97.

. O sujeito e o poder. In: DREYFUS, Hubert; RABINOW,

Paul. Michel Foucault: Uma trajetória filosófica - para além do estruturalismo e da hermenêtica. Rio de Janeiro: Forense Universitária, 1995. p. 231-249.

FRIEDMAN, Milton. Capitalismo e liberdade. São Paulo: Artenova, 1977.

HARDT, Michael; NEGRI, Antonio. Império. 4. ed. Rio de Janeiro: Record, 2002.

KELLNER, Douglas. A cultura da mídia. Bauru: EDUSC, 2001. LOPES, Maura Corcini. Políticas de inclusão e governamentalidade. Educação e realidade, v. 34, n. 2, p. 153-169, maio/ago. 2009.

LUSTOSA, Elcias. O texto da notícia. Brasília: Editora UNB, 1996.

NARODOWSKI, Mariano. Comenius \& a educação. Belo Horizonte: Autêntica, 2001.

PETERS, Michael. Governamentalidade neoliberal e educação. In: SILVA, Tomaz Tadeu da (Org.). O sujeito da educação: estudos foucaultianos. Petrópolis: Vozes, 2002. p. 211-224.

RODRIGUES, Sérgio. Tendências contemporâneas do jornalismo cultural. 2008. Disponível em: <http://www.bb.com.br/appbb/ portal/bb/si/pbcs/rsm/Sergio_Rodrigues.jsp >. Acesso em: 20 mar. 2008.

SENNETT, Richard. A corrosão do caráter: as consequências pessoais do trabalho no novo capitalismo. 5. ed. Rio de Janeiro: Record, 2001.

A cultura do novo capitalismo. Rio de Janeiro: Record, 2006.

SILVA, Juremir Machado da. O pensamento contemporâneo francês sobre a comunicação. In: HOHLFELDT, Antonio; MARTINO, Luiz Carlos; FRANÇA, Vera Veiga (Orgs.). Teorias da Comunicação: conceitos, escolas e tendências. Petrópolis: Vozes, 2001. p. 171-186.

SILVA, Roberto Rafael Dias da. Universitários S/A: estudantes universitários nas tramas de Vestibular/ZH. Dissertação de Mestrado (Programa de Pós-graduação em Educação), Universidade do Vale do Rio dos Sinos, São Leopoldo, 2008.

VEIGA-NETO, Alfredo. Educação e governamentalidade neoliberal: novos dispositivos, novas subjetividades. In: CASTELO BRANCO, Guilherme; PORTOCARRERO, Vera (Orgs.). Retratos de Foucault. Rio de Janeiro: Nau, 2000. p. 179-217.

; LOPES, Maura Corcini. Inclusão e governamentalidade.

Educação e Sociedade, v. 28, n. 100, p. 947-963, out. 2007. 
O jogo produtivo da educabilidade/governamentalidade na constituição de sujeitos universitários

ROBERTO RAFAEL DIAS DA SILVA, doutorando no Programa de Pós-Graduação em Educação da Universidade do Vale do Rio dos Sinos (UNISINOS), é professor na área de Fundamentos da Educação na Universidade Federal da Fronteira Sul (UFFS), campus de Erechim-RS. Publicações: Universitários S/A: empreendedorismo e gestão dos talentos nas mídias contemporâneas (Anais... REUNIÃO ANUAL DA ANPED, 32., 2009. 1 CD-ROM); em coautoria com Vitória Casagrande Viel, Sustentabilidade e governamentalidade: marketing ambiental na cultura do novo capitalismo (Revista Eletrônica do Mestrado em Educação Ambiental, v.23, p. 200-215, jul./dez. 2009). Pesquisa atual: "Educação, tecnociência e capitalismo cognitivo: uma crítica política do saber", com bolsa da CAPES.E-mail: robertoddsilva@, yahoo.com.br

ELI TEREZINHA HENN FABRIS, doutora em educação pela Universidade Federal do Rio Grande do Sul (UFRGS), é professora do Programa de Pós-Graduação em Educação da Universidade do Vale do Rio dos Sinos (UNISINOS). Publicações: A produção do aluno nos pareceres descritivos: mecanismos de normalização em ação (In: LOPES, Maura Corcini; HATTGE, Morgana Domênica (Orgs.). Inclusão escolar: conjunto de práticas que governam. Belo Horizonte: Autêntica, 2009. p. 51-67); Cinema e educação: um caminho metodológico (Educação e Realidade, v.33, n. 1, p. 117-133, jan./jun. 2008); Tia: jeito brasileiro de ser professora (In: LOPES, Maura Corcini; DAL'IGNA, Maria Cláudia (Orgs.). In/ exclusão: nas tramas da escola. Canoas: Editora da ULBRA, 2007. p. 12-31). Pesquisa atual: “As tramas do currículo e o desempenho escolar: as práticas pedagógicas nos anos iniciais do ensino fundamental".E-mail: efabris@unisinos.br 
about advances in the debate and made possible new research and studies on increasingly more specific aspects involved in the issue. With the aim of contributing to this debate, the article presents conjectures with regard to the relationship between state public sectors, resulting specifically from the new type of partnership between state public organs and researchers in education from public universities, for formulating, implementing and evaluating public policy for literacy, starting in the 1980s and emphasized from the 1990s onwards, related to the reform of the Brazilian state.

Key words: literacy, history of literacy, public policies for literacy

\section{Alfabetización en Brasil: conjeturas} sobre las relaciones entre políticas públicas y sus sujetos privados

Las complejas y polémicas cuestiones relativas a la formulación, implementación y evaluación de las politicas públicas en la educación de Brasil, viene siendo objeto, en las últimas décadas, de importantes estudios y pesquisas. Como resultado, se ha venido acumulando un significativo cuerpo de conocimientos a este respecto, lo que propicia avances en el debate y posibilita nuevos estudios y pesquisas a respecto de aspectos cada vez más especificos de la temática. Con el objetivo de contribuir para este debate, se presentan en este artículo conjeturas a respecto de la relación entre sectores públicos estatales en consecuencia especificamente del nuevo tipo de sociedad entre órganos públicos del Estado y docentes investigadores de las universidades públicas para la formulación, implementación y evaluación de las políticas públicas para la alfabetización, iniciada en la década de 1980 y enfatizada a partir de la década de 1990, con la reforma del Estado brasileño.

Palabras clave: alfabetización; historia de la alfabetización; politicas públicas para la alfabetización
Gustavo Andrada Bandeira

\section{Um currículo de masculinidades nos} estádios de futebol

$\mathrm{O}$ artigo procura analisar diferentes masculinidades nos estádios de futebol e ver de que forma elas se hierarquizam, mostrando como as ações dos torcedores, seus cânticos, suas vestimentas e faixas estão envolvidos nas construções das masculinidades desses sujeitos. Os estádios exercem uma pedagogia: aprende-se quando gritar, quando calar, o que gritar, o que calar, o que e como sentir... Argumentase que o conceito de currículo construído nos estádios de futebol pode ser pensado como práticas que os sujeitos são reiteradamente convidados a fazer. Essas práticas são sistematizadas no artigo em quatro eixos: raça, garra e luta; violência e socialização; um amor de macho; masculinidades subalternas.

Palavras-chave: masculinidades; currículo; futebol

\section{A curriculum of masculinities in football stadia}

This article analyses different masculinities in football stadia and seeks to discern in what way they are hierarchised, revealing how the actions of fans, their songs, their clothing and their banners are involved in the construction of these subjects' masculinities. The stadia develop a pedagogy: one learns when and what to shout, when to keep silent and about what, what and how to feel... The article argues that the concept of curriculum constructed in the football stadia can be thought of as acts which the subjects are repeatedly invited to practice. These practices are systematized in the article in four axes: guts, determination and struggle; violence and socialization; a male love; subaltern masculinities.

Key words: masculinities, curriculum, football

Un currículo de masculinidades en los estadios de fútbol
El articulo busca analizar las diferentes masculinidades de los estados de fútbol $y$ ver de que forma ellas se jerarquizan, buscando estar en evidencia con las acciones de los hinchas, sus cantos, sus ropas y carteles están relacionados con las construcciones de las masculinidades de esos sujetos. Los estadios ejercen una pedagogía: se aprende cuando deben gritar y cuando callar, lo que gritar, lo que callar, lo que y como sentir... Se argumenta que el concepto de currículo construido en los estadios de fútbol puede ser pensado como prácticas que los sujetos son reiteradamente invitados a realizar. Éstas prácticas, son sistematizadas en este estudio en cuatro puntos principales: raza, brio y lucha; violencia y socialización; un amor de macho; masculinidades subalternas.

Palabras clave: masculinidades; currículo; fútbol

Roberto Rafael Dias da Silva

Elí Terezinha Henn Fabris

O jogo produtivo da educabilidade/ governamentalidade na constituição de sujeitos universitários

O presente artigo resulta de uma pesquisa recente que buscava compreender alguns dos modos pelos quais os sujeitos universitários são constituídos na contemporaneidade, tomando como materialidade os cadernos "Vestibular/ZH". Consideramos, analiticamente, que a produção dos currículos escolares emerge de uma trama de relações de educabilidade e governamentalidade. Dessa forma, entendemos que os enunciados emergentes dessa mídia impressa produzem sentidos à produção dos sujeitos e também às práticas escolares contemporâneas, ao que talvez encaminhe a produção de um "currículo da conquista". Essa configuração conduz à individualização e à responsabilização dos sujeitos, mediados pela produção de uma pauta de consumo que posiciona o acesso ao saber universitário no campo 
individual, acesso obtido mediante competição acirrada, na qual as responsabilidades são privatizadas. Do ponto de vista teórico, operamos sob a inspiração dos estudos do filósofo Michel Foucault.

Palavras-chave: educação; conquista; governamentalidade; Vestibular/ZH; Michel Foucault

The productive game of educabilitygovernmentality in the constitution of university subjects

This paper is based on recent research which seeks to understand some of the ways in which university subjects are at present constituted drawing upon the University Entrance (Vestibular) sections in the Zero Hora newspaper. We consider that the production of school curricula emerges from a network of relations of educability and governmentality. Thus, we understand that the statements which appear in the print-based media produce meanings for the production of the subjects as well as for contemporary school practices, resulting perhaps in the elaboration of a 'curriculum of conquest'. This curricular configuration leads to individualisation and to making these subjects accountable, mediated by the production of a consumerist agenda, which places access to university knowledge in the individual field, obtained through tough competition in which responsibilities are private. From the theoretical standpoint our analysis is inspired by the studies of the philosopher Michel Foucault.

Key words: education; conquest; governmentality; University Entrance Sections of the newspaper Zero Hora (Vestibular/ZH); Michel Foucault

El juego productivo de la relación educacional gubernamental en la constitución de sujetos universitarios El artículo resulta de una pesquisa reciente que buscaba comprender algunos de los modos por los cuales los sujetos universitarios son constituidos en la contemporaneidad, tomando como materialidad los cuadernos de la Selectividad/ZH. Consideramos que la producción de los currículos escolares emerge de un argumento de relaciones educacionales y gubernamentales. De esta forma, entendemos que los enunciados emergentes de ese medio de comunicación impreso producen sentidos a la producción de los sujetos y también a las prácticas escolares contemporáneas, a lo que tal vez encamine la producción de un "currículo de la conquista". Tal configuración conduce a la individualización y a la responsabilización de sujetos, intermediados por la producción de una norma de consumo que define el acceso al saber universitario en el campo individual, acceso obtenido por medio de competición incitada, en la cual las responsabilidades son privatizadas. Del punto de vista teórico, operamos sobre la inspiración de los estudios del filósofo Michel Foucault.

Palabras clave: educación; conquista; gubernamental; Selectividad/ZH; Michel Foucault

Vânia Maria Jorge Nassif, Darcy Mitiko Mori Hanashiro e Rosane Rivera Torres

\section{Fatores que influenciam na} percepção das competências para o exercício da docência

Este artigo analisa as competências requeridas para docência acadêmica em relação às características demográficas e funcionais de docentes universitários. A partir da resposta de 282 docentes ao questionário aplicado em uma amostra de conveniência, realizou-se análise de confiabilidade e validação de constructo, gerando escala para avaliar a percepção das referidas competências. Por meio de técnicas multivariadas, dois grupos de docentes foram identificados: professor experiente e professor iniciante. $\mathrm{O}$ primeiro, formado por profissionais com idade mais elevada e mais tempo de docência e permanência na instituição, valoriza sobremaneira as competências relativas à habilidade interpessoal, à capacidade didáticopedagógica e abertura à inovação, quando comparado ao segundo grupo. Os professores iniciantes, com menor tempo de vinculação à universidade $\mathrm{e}$ pouco tempo no exercício da docência, têm o foco voltado para a obtenção de titulação, demonstrando não entender o que as universidades esperam deles e, sobretudo, quais competências necessitam desenvolver para conquistar o patamar dos experientes.

Palavras-chave: competência de docentes; escala de percepção de competência de docentes; competitividade da universidade privada.

\section{Factors which influence the} perception of competences for the teaching profession

This article analyses the competences required for academic teaching in relation to the demographic and functional characteristics of university teachers. Based on replies from 282 lecturers to the questionnaire applied in a sample of convenience, an analysis of construct reliability and validation was carried out, generating a scale for evaluating the perception of those competences. By means of multivariable techniques, two groups of lecturers were identified: experienced and new lecturers. The first, made up of older and more experienced lecturers, values above all competences related to interpersonal skills, didacticpedagogical capacity and openness to innovation when compared to the second group. The new professionals, with less time in the University and less teaching experience, were more focused on obtaining titles. They revealed a lack of understanding of what universities expect from them and, above all, what competences they need to develop in order to reach the level of experienced lecturers. 